\title{
SISTEMA RADICULAR DO CAPIM-MARANDU, CONSIDERANDO AS COMBINAÇÕES DE DOSES DE NITROGÊNIO E DE ENXOFRE ${ }^{(1)}$
}

\author{
Karina Batista $^{(2)}$ \& Francisco Antonio Monteiro ${ }^{(3)}$
}

\begin{abstract}
RESUMO
Um sistema radicular bem desenvolvido na gramínea forrageira é necessário para a formação e sustentação da planta e, como conseqüência, para a boa produtividade da pastagem. Objetivou-se avaliar características radiculares da Brachiaria brizantha cv. Marandu, em resposta a combinações de doses de $\mathrm{N}$ e $\mathrm{S}$ na solução nutritiva, empregando sílica como substrato, num experimento realizado em casa de vegetação no período de setembro a dezembro de 2001. Utilizou-se o esquema fatorial $5^{2}$ fracionado, com 13 combinações de $\mathrm{N}$ e $\mathrm{S}$, em $\mathrm{mg} \mathrm{L}^{-1}$, respectivamente: 14 e 3,$2 ; 14$ e $32 ; 14$ e $80 ; 126$ e 12,$8 ; 126$ e 64; 210 e 3,$2 ; 210$ e $32 ; 210$ e $80 ; 336$ e 12,8; 336 e 64; 462 e 3,2; 462 e 32 e 462 e 80, as quais foram distribuídas segundo o delineamento de blocos ao acaso, com quatro repetições. Foram realizados dois cortes nas plantas. Após o segundo corte, as raízes foram separadas do substrato e avaliadas. A concentração de $\mathrm{N}$ e os acúmulos de $\mathrm{N}$ e de $\mathrm{S}$ nas raízes do capim mostraram-se dependentes da interação entre as doses de $\mathrm{N}$ e S. A dose de $\mathbf{N}$ foi determinante para o comprimento, superfície, produção de massa seca, relação comprimento:massa seca e concentração de $\mathrm{S}$ no tecido das raízes da forrageira. A produção de massa seca, o comprimento, a superfície das raízes e o acúmulo total de $\mathrm{N}$ e de $\mathrm{S}$ nas plantas do capim tiveram significativas correlações entre si.
\end{abstract}

Termos de indexação: Brachiaria brizantha, raízes, fertilização nitrogenada, fertilização com enxofre.

\footnotetext{
(1) Parte da Tese de Mestrado da primeira autora, apresentada à Escola Superior de Agricultura "Luiz de Queiroz" - ESALQ/USP, para obtenção do título de Mestre em Agronomia, na área de concentração de Solos e Nutrição de Plantas. Projeto apoiado pela FAPESP. Recebido para publicação em março de 2005 e aprovado em agosto de 2006.

${ }^{(2)}$ Doutora em Solos e Nutrição de Plantas, Escola Superior de Agricultura "Luiz de Queiroz" - ESALQ/USP. Caixa Postal 9, CEP 13418-970 Piracicaba (SP). Bolsista CAPES. E-mail: batistakarina@hotmail.com

(3) Professor Titular do Departamento de Ciência do Solo, ESALQ/USP. Bolsista CNPq. E-mail: famontei@esalq.usp.br
} 


\title{
SUMMARY: MARANDU GRASS ROOT SYSTEM AS AFFECTED BY THE COMBINATIONS OF NITROGEN AND SULPHUR RATES
}

\begin{abstract}
A well-developed root system is necessary for plant growth and sustentation, and, as a consequence, for high pasture yield. The objective of this experiment was to evaluate root characteristics in Brachiaria brizantha $c v$. Marandu in response to combinations of nitrogen and sulphur rates in nutrient solution. Ground quartz was used as substrate in a greenhouse experiment from September to December 2001. An incomplete $5^{2}$ factorial was arranged in a randomized block design with four replications. The 13 combinations of nitrogen and sulphur were, in $\mathrm{mg} \mathrm{L}^{-1}$, respectively: 14 and 3.2; 14 and 32; 14 and 80; 126 and 12.8; 126 and 64; 210 and 3.2; 210 and 32; 210 and 80; 336 and 12.8; 336 and 64; 462 and 3.2; 462 and 32; 462 and 80. Plants were harvested twice and, after the second harvest, roots were taken from the substrate and evaluated. Root nitrogen concentration and nitrogen and sulphur content depended on the interaction between nitrogen and sulphur rates. Nitrogen rate was determinant for the length, surface, dry weight, length:dry weight ratio, and sulphur concentration in the grass root. Root dry weight, length and surface and the total content of nitrogen and sulphur in the grass were significantly correlated.
\end{abstract}

Index terms: Brachiaria brizantha, roots, nitrogen fertilization, sulphur fertilization.

\section{INTRODUÇÃO}

No Brasil, as pastagens constituem a principal fonte de alimentação para os ruminantes. Aproximadamente 78 milhões de hectares são ocupados por pastagens naturais e 99,7 milhões de hectares por pastagens plantadas. A região sudeste do País apresenta cerca de 19,8 milhões de hectares de pastagens naturais, 12,1 milhões de hectares de pastagens plantadas, e, desta área, aproximadamente $40 \%$ é composta por Brachiaria brizantha cv. Marandu. Esta gramínea é muito difundida em regiões mais ou menos úmidas, tendo grande capacidade de adaptação edafoclimática e boa tolerância à seca e à cigarrinha (Alcântara \& Bufarah, 1992).

O sistema radicular das plantas cultivadas tem despertado atenção nos estudos das inter-relações entre os solos, plantas e outros organismos vivos. Nesse contexto, destacam-se os aspectos físicos, químicos e biológicos inerentes ao solo, que são favoráveis à distribuição de raízes (Crestana et al., 1994). Esses autores, avaliando a distribuição de raízes no solo, concluíram que o processamento de imagens constitui ferramenta importante no estudo do crescimento radicular de plantas, além de ser relativamente simples e exato.

É grande a necessidade de maior número de abordagens de sistema radicular das forrageiras, já que a quantificação de raízes normalmente envolve o uso de métodos complexos e dispendiosos, conquanto seja de extrema importância para o entendimento do sistema solo-planta (Teruel et al., 2000; Cecato et al., 2004). Além das dificuldades de observação e quantificação de raízes, essa parte da planta constitui um sistema bastante complexo. O suprimento de água e de nutrientes para as plantas depende das interações entre os complexos processos fisiológicos e celulares ocorrentes no sistema radicular, que resultam numa arquitetura específica (habilidade da planta em adquirir os recursos do solo), e nos não menos complexos processos iônicos e de transporte no solo (Teruel et al., 2000).

Um sistema radicular bem desenvolvido garante boa formação e sustentação da parte aérea. Assim, uma planta bem suprida em $\mathrm{N}$ apresenta sistema radicular maior que uma planta deficiente em $\mathrm{N}$, porque os mecanismos envolvidos no crescimento do sistema radicular estão relacionados com o acúmulo de carboidratos (Brouwer, 1962).

A deficiência de $\mathrm{S}$, demonstrada por apreciável número de culturas, acaba interferindo na quantidade absorvida de $\mathrm{N}$ e, como conseqüência, pode induzir a planta a desenvolver deficiência de $\mathrm{N}$ que, em muitos casos, acaba mascarando a deficiência de S. Deste modo, o estudo da relação N:S tem despertado interesse crescente de pesquisadores em todo o mundo, particularmente daqueles que trabalham com pastagens (Monteiro \& Carriel, 1987; Werner \& Monteiro, 1988; Guedes et al., 2000; Guenni et al., 2002), já que ambos os nutrientes estão diretamente relacionados com a produção e a qualidade das pastagens.

O estado nutricional das plantas tem efeito nas propriedades de crescimento de suas raízes (Eshel \& Waisel, 1996). Nesse contexto, reconhece-se a importância de estudos relativos ao suprimento desses dois nutrientes em características radiculares da Brachiaria brizantha cv. Marandu, particularmente com a combinação de doses de $\mathrm{N}$ e de $\mathrm{S}$. 
Objetivou-se avaliar individualmente o comprimento, a superfície, a produção de massa seca, as concentrações e acúmulos de $\mathrm{N}$ e de $\mathrm{S}$ e a relação $\mathrm{N}: \mathrm{S}$, bem como as correlações entre esses atributos no sistema radicular da Brachiaria brizantha Stapf. cv. Marandu, considerando o fornecimento de $\mathrm{N}$ e S em solução nutritiva.

\section{MATERIAL E MÉTODOS}

O experimento foi realizado em casa de vegetação localizada em Piracicaba-SP, no campus da Escola Superior de Agricultura "Luiz de Queiroz", cultivandose a espécie forrageira Brachiaria brizantha Stapf. cultivar Marandu, no período de setembro a dezembro de 2001. A temperatura média da casa de vegetação, no período experimental, foi de $30,7^{\circ} \mathrm{C}$.

Foram testadas combinações de doses de $\mathrm{N}$ e de $\mathrm{S}$ em solução nutritiva, utilizando vasos plásticos com capacidade de 3,6 L e tendo sílica como substrato. As doses dos nutrientes foram resultantes das combinações de cinco doses de N $(14 ; 126 ; 210 ; 336$ e $\left.462 \mathrm{mg} \mathrm{L}^{-1}\right)$ e de cinco doses de $\mathrm{S}(3,2 ; 12,8 ; 32 ; 64 \mathrm{e}$ $80 \mathrm{mg} \mathrm{L}^{-1}$ ) em esquema fatorial $5^{2}$ fracionado, fundamentado em Littell \& Mott (1975). De acordo com esse esquema, foram obtidas 13 combinações para $\mathrm{N}$ e S, em mg L-1: 14 e 3,$2 ; 14$ e $32 ; 14$ e $80 ; 126$ e 12,$8 ; 126$ e $64 ; 210$ e 3,$2 ; 210$ e $32 ; 210$ e $80 ; 336$ e 12,$8 ; 336$ e $64 ; 462$ e 3,$2 ; 462$ e $32 ; 462$ e 80 . Foi utilizada a solução completa de Sarruge (1975), modificada somente para as doses de $\mathrm{N}$ e de $\mathrm{S}$. Os vasos foram distribuídos segundo delineamento estatístico de blocos ao acaso, com quatro repetições.

Foram realizados dois cortes das plantas, com o primeiro ocorrendo aos 39 dias do transplantio das mudas, e o segundo, 40 dias após o primeiro corte. Imediatamente após o segundo corte da parte aérea, as raízes foram separadas e lavadas em água corrente e deionizada, utilizando-se de um conjunto de peneiras com malha de 0,25 e $1,00 \mathrm{~mm}$. A seguir, as raízes foram colocadas para secar em estufa com circulação forçada de ar a $70{ }^{\circ} \mathrm{C}$, até peso constante, para determinação da produção de massa seca. Os resultados relativos à produção da parte aérea do capim encontram-se em Batista \& Monteiro (2006).

Para avaliar a superfície e o comprimento total do sistema radicular, uma subamostra de raízes (cerca de $20 \%$ ) foi coletada após a lavagem, ao final do experimento. $\mathrm{Na}$ seqüência, as raízes dessa subamostra foram coloridas com solução de violeta genciana e digitalizadas, com as imagens analisadas pelo aplicativo SIARCS (Sistema Integrado para Análise de Raízes e Cobertura do Solo) versão 3,0 (Embrapa-CNPDIA, s/d). Após serem digitalizadas, as raízes foram colocadas para secar até peso constante, em estufa com circulação forçada de ar a $70{ }^{\circ} \mathrm{C}$, com posterior pesagem. Com a massa das subamostras, fez-se a correção do comprimento e superfície para o total do sistema radicular de cada vaso, considerando a produção de massa seca total das raízes, conforme descrito por Crestana et al. (1994).

As raízes foram moídas em moinho do tipo Wiley, acondicionadas em sacos plásticos e encaminhadas para determinação das concentrações de $\mathrm{N}$ e de S, conforme método descrito por Sarruge \& Haag (1974). $\mathrm{O} \mathrm{N}$ foi determinado pelo método analítico semi-micro Kjeldahl, após digestão sulfúrica, enquanto a digestão nítrico-perclórica serviu para a preparação do extrato a partir do qual foi determinado o S, pelo método da turbidimetria do cloreto de Ba. Determinada a concentração do $\mathrm{N}$ e do $\mathrm{S}$ em cada componente da parte aérea, a concentração total desses nutrientes foi obtida por cálculo das médias ponderadas. Para obter o acúmulo total de $\mathrm{N}$ e de $\mathrm{S}$, o acúmulo de cada um desses nutrientes foi calculado pela multiplicação da massa seca de cada um dos componentes da parte aérea e da sua concentração. Assim, o acúmulo total foi resultante da soma do acúmulo desses nutrientes nos dois cortes.

Todos os resultados receberam o tratamento estatístico recomendado, com análise em superfície de resposta pelo emprego do "Statistical Analysis System" (SAS, 1996). Inicialmente, foi realizada a análise de variância para as combinações de doses de $\mathrm{N}$ e de $\mathrm{S}$, e, com vistas em avaliar a significância ou não do teste $\mathrm{F}$ para essas combinações, efetuou-se o estudo de regressão polinomial (superfície de resposta) por meio do comando RSREG ou o estudo de regressão (primeiro e segundo graus) por meio do uso do GLM. Também, procedeu-se ao estudo das correlações entre as variáveis estudadas. Foi adotado o nível de significância de $5 \%$ em todas as análises estatísticas.

\section{RESULTADOS E DISCUSSÃO}

\section{Superfície e comprimento do sistema radicular}

Para a superfície e comprimento do sistema radicular do capim-Marandu não se observou significância da interação entre as doses de $\mathrm{N}$ e de S, enquanto ocorreu efeito significativo das doses de $\mathrm{N}$ fornecidas na solução nutritiva (Figura 1a e 1b).

A superfície total do sistema radicular ajustou-se ao modelo quadrático (Figura 1a), tendo a dose de $\mathrm{N}$ de $450 \mathrm{mg} \mathrm{L}^{-1}$ proporcionado o máximo valor para essa variável. Doses mais baixas de $\mathrm{N}$, para atingir o máximo valor de superfície total do sistema radicular, foram encontradas por Santos Junior (2001), que obteve os máximos valores de superfície radicular do capim-Marandu nas doses de $\mathrm{N}$ de 200; 195; 217; 259 e $312 \mathrm{mg} \mathrm{L}^{-1}$ na solução nutritiva, nas idades de crescimento de $21 ; 28 ; 35 ; 42$ e 49 dias, respectivamente. 

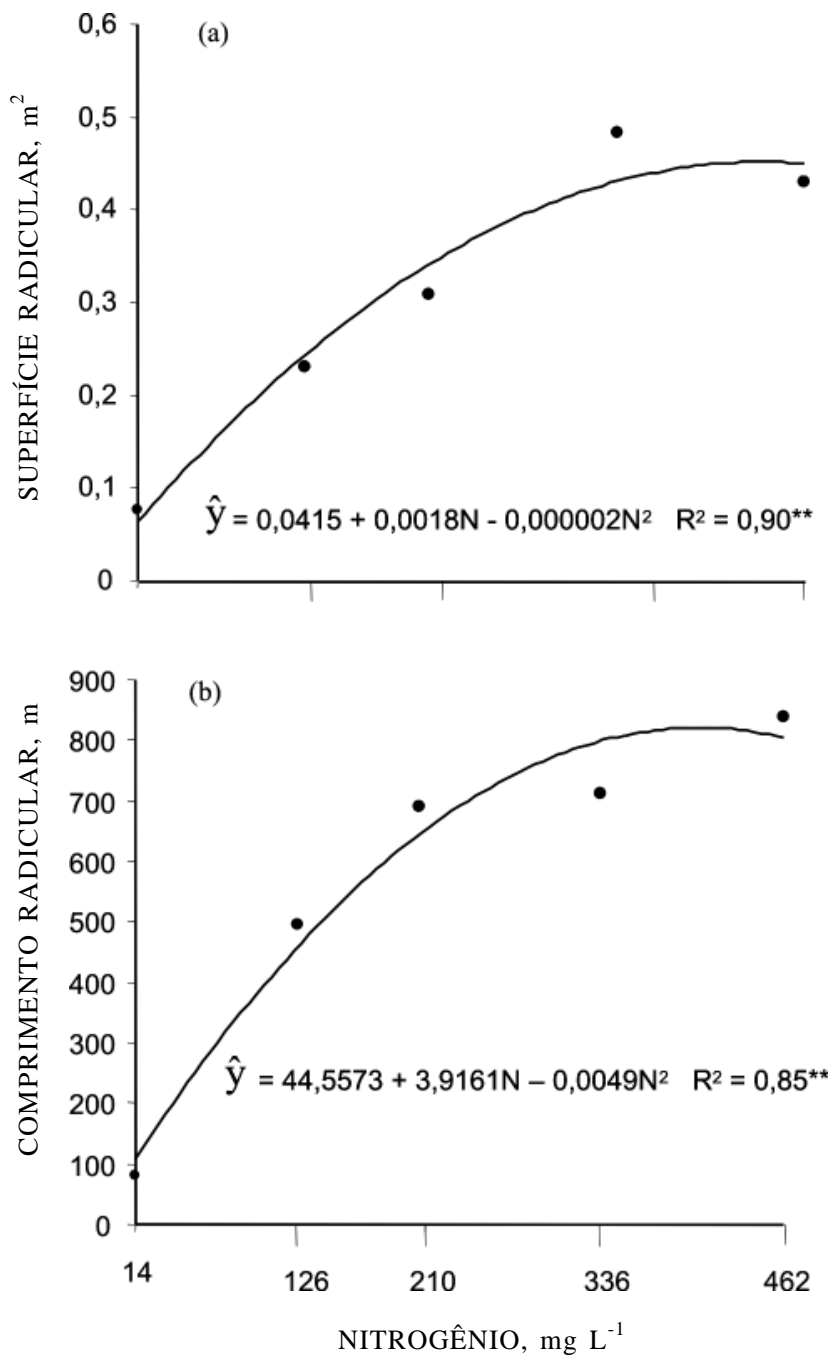

Figura 1. Superfície (a) e comprimento (b) do sistema radicular do capim-Marandu, considerando as doses de nitrogênio aos 79 dias do transplantio.

Estimou-se que a dose de $\mathrm{N}$ de $400 \mathrm{mg} \mathrm{L}^{-1}$ seria responsável pelo maior comprimento total de raízes (Figura 1b). Nas doses de $\mathrm{N}$ de $400 \mathrm{mg} \mathrm{L}^{-1}$ e de $14 \mathrm{mg} \mathrm{L}^{-1}$, foram encontrados, respectivamente, $827 \mathrm{~m}$ e $98,4 \mathrm{~m}$ para o comprimento total estimado de raízes (o que significa um aumento de 8,4 vezes entre a mais baixa e a mais alta dessas doses). Santos Junior (2001) relatou que os máximos comprimentos radiculares corresponderam às doses de $\mathrm{N}$ de $207 ; 199$; 199; 236 e $294 \mathrm{mg} \mathrm{L}^{-1}$, em períodos de crescimento do capim-Marandu, de 21;28; 35; 42 e 49 dias, respectivamente. No presente experimento, a maximização do comprimento radicular se deu em presença de dose mais elevada de N, numa situação em que as plantas foram cortadas, pela primeira vez, 39 dias após o transplantio das mudas para os vasos e, novamente, 40 dias de rebrota após o primeiro corte.

Essas doses de $\mathrm{N}$ responsáveis pelo maior comprimento $\left(400 \mathrm{mg} \mathrm{L}^{-1}\right)$ e superfície $\left(450 \mathrm{mg} \mathrm{L}^{-1}\right)$ de raízes do capim-Marandu também estão abaixo das relatadas por Lavres Junior (2001), trabalhando com doses de N de 28 a $462 \mathrm{mg} \mathrm{L}^{-1}$ para o capim-Mombaça (Panicum maximum), no qual as doses de $\mathrm{N}$ de $596 \mathrm{e}$ $814 \mathrm{mg} \mathrm{L}^{-1}$ acarretariam máximos comprimento e superfície de raízes, respectivamente.

Cabe destacar que os resultados deste trabalho, de forma coerente com os de Lavres Junior (2001) e Santos Junior (2001), demonstraram que, para os capins tropicais, a dose de $\mathrm{N}$ de $210 \mathrm{mg} \mathrm{L}^{-1}$ sugerida por Sarruge (1975) não está adequada para atender à demanda de $\mathrm{N}$ com vistas em maximizar o crescimento radicular em estudos de solução nutritiva.

\section{Produção de massa seca das raízes}

A interação entre as doses de $\mathrm{N}$ e de $\mathrm{S}$ não foi significativa para produção de massa seca de raízes do capim-Marandu, mas as doses de $\mathrm{N}$ tiveram influência significativa nesse atributo da planta (Figura 2).

A produção de massa seca das raízes, considerando as doses de $\mathrm{N}$, apresentou ajuste ao modelo raiz quadrada. Observou-se que a dose que apresentou o máximo valor dessa produção excedeu o limite empregado neste experimento. Entretanto, Santos Junior (2001) verificou que a máxima produção de massa seca de raízes no capim-Marandu ocorreu na dose de $\mathrm{N}$ de $303 \mathrm{mg} \mathrm{L}^{-1}$, aos 56 dias de crescimento. Santos \& Monteiro (1999) também relataram que, para maximizar a produção de massa seca de raízes da Brachiaria decumbens, a dose de $\mathrm{N}$ teria de estar elevada (453 $\left.\mathrm{mg} \mathrm{L}^{-1}\right)$.

Constatou-se também que, na mais baixa dose de $\mathrm{N}$ (14 $\left.\mathrm{mg} \mathrm{L}^{-1}\right)$, a produção estimada de raízes representou, aproximadamente, $6 \%$ da máxima estimada. Essa resposta na produção de massa seca de raízes mostra a relevância de uma planta estar

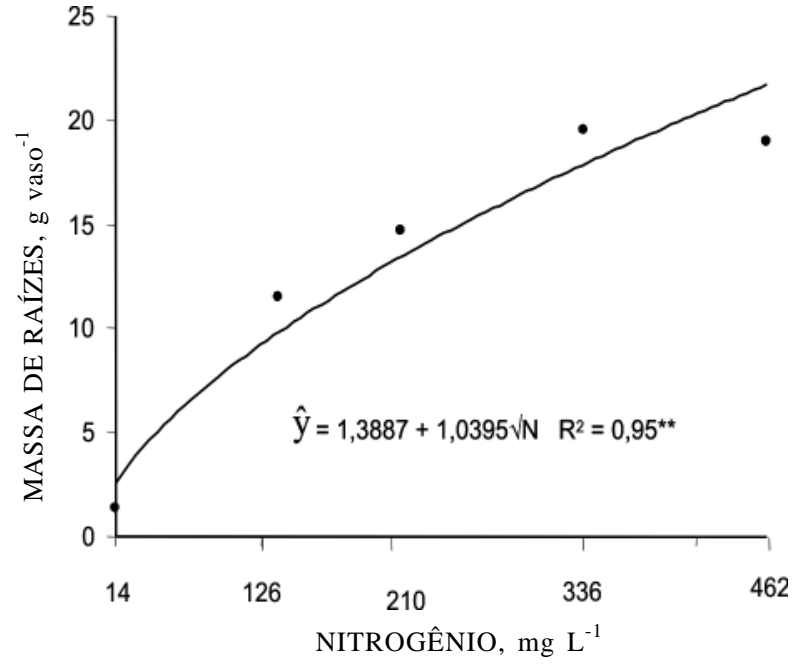

Figura 2. Produção de massa seca de raízes do capimMarandu, considerando as doses de nitrogênio aos 79 dias do transplantio. 
bem suprida de $\mathrm{N}$ para apresentar o sistema radicular bem desenvolvido. Isto tem sido atribuído aos mecanismos envolvidos no crescimento do sistema radicular, que estão relacionados com o acúmulo de carboidratos na ausência de $\mathrm{N}$, tanto na parte aérea como nas raízes das plantas (Brower, 1962).

$\mathrm{O}$ fato de as doses elevadas de $\mathrm{N}$ serem responsáveis pelo maior crescimento do sistema radicular foi visualmente constatado ao final do período experimental, quando se verificou que as raízes desenvolvidas em alta dose de $\mathrm{N}$ exibiam maior crescimento radicular (Figura 3).

O comprimento específico (comprimento total dividido pela massa seca de raízes) apresentou redução em seu valor à medida que aumentavam as doses de $\mathrm{N}$ na solução nutritiva (Figura 4). Dessa forma, o aumento no comprimento do sistema radicular, considerando as doses de N (Figura 3), não acompanhou a elevação da massa seca de raízes com o incremento das doses de N (Figura 2). Segundo Fitter (1996), isto ocorre porque em condições de alto comprimento específico, tem-se a presença de raízes mais finas que buscam nutrientes em condições de baixa disponibilidade. Também, segundo Marschner (1995), o N altera a composição das plantas muito mais que qualquer outro nutriente e, simultaneamente ao aumento no conteúdo de $\mathrm{N}$, ocorre redução drástica de dois carboidratos principais de reserva (frutosanas e amido), e, em contraste a esse aumento de carboidratos, o conteúdo de lignina em gramíneas pode aumentar, visto que os aminoácidos fenilalanina e tirosina são os precursores da síntese de lignina.

Para a superfície específica (superfície total do sistema radicular dividida pela massa seca de raízes), não se observou significância da interação entre as doses de $\mathrm{N}$ e de $\mathrm{S}$, tampouco para as doses individuais de $\mathrm{N}$ e de $\mathrm{S}$.

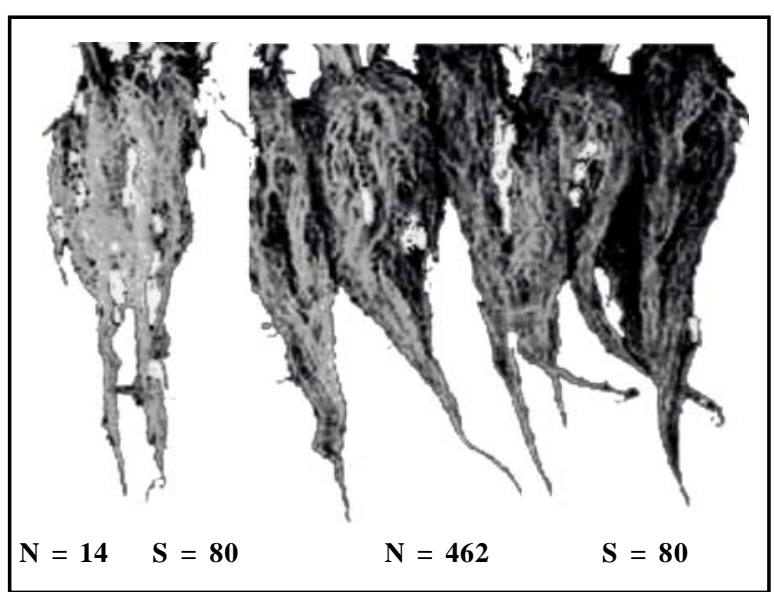

Figura 3. Sistema radicular do capim-Marandu submetido a doses de nitrogênio (alta e baixa), em combinação com uma dose de enxofre, aos 79 dias do transplantio.

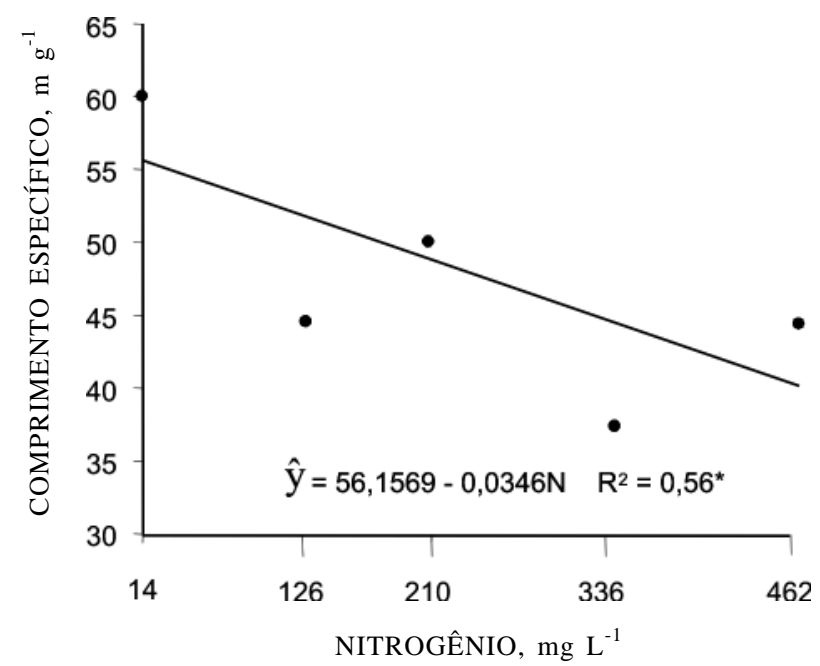

Figura 4. Comprimento específico do sistema radicular do capim-Marandu, considerando as doses de nitrogênio aos 79 dias do transplantio.

\section{Concentração e acúmulo total de nitrogênio}

A concentração e o acúmulo de N no capim-Marandu apresentaram significância para a interação entre as doses de $\mathrm{N}$ e de $\mathrm{S}$ fornecidas na solução nutritiva (Figuras 5 e 6).

O modelo de regressão polinomial permitiu ajuste dos valores de concentrações de $\mathrm{N}$ no tecido radicular em relação às doses de $\mathrm{N}$ e de $\mathrm{S}$ no substrato (Figura 5). A concentração de $\mathrm{N}$ nas raízes variou de 2,4 a $29,5 \mathrm{~g} \mathrm{~kg}^{-1}$. O estudo da superfície de resposta da concentração de $\mathrm{N}$ nas raízes demonstrou que, para todas as doses de $\mathrm{S}$, à medida que aumentavam as doses de N, ocorria elevação na concentração de N nas raízes. Entretanto, observou-se que as mais altas concentrações de $\mathrm{N}$, encontradas nas altas doses de $\mathrm{N}$ e baixas doses de $\mathrm{S}$, com relação entre doses de 144,4:1, demonstrando, portanto, o excesso no fornecimento de $\mathrm{N}$ e a importância da relação $\mathrm{N}$ e S para o capim (Figura 5).

A análise de variância do acúmulo total de $\mathrm{N}$ no capim-Marandu demonstrou a ocorrência de um ponto de sela, o que, segundo Gomes \& Conagin (1991), caracteriza ao mesmo tempo um ponto de máximo e um ponto de mínimo. Entretanto, para uma mesma dose de $\mathrm{S}$, o incremento nas doses de $\mathrm{N}$ resultava em aumento no acúmulo total de $\mathrm{N}$ no capim-Marandu; em condições de elevada dose de N (462 $\left.\mathrm{mg} \mathrm{L}^{-1}\right)$ associada a doses altas de $\mathrm{S}\left(70,4\right.$ a $\left.80,0 \mathrm{mg} \mathrm{L}^{-1}\right)$, observou-se maior valor de acúmulo de $\mathrm{N}$ total no capim (Figura 6). A relação entre a massa seca de raízes e a massa seca da parte aérea não apresentou significância para a interação entre as doses de $\mathrm{N}$ e de $\mathrm{S}$, tampouco para as doses individuais de $\mathrm{N}$ e de S. 


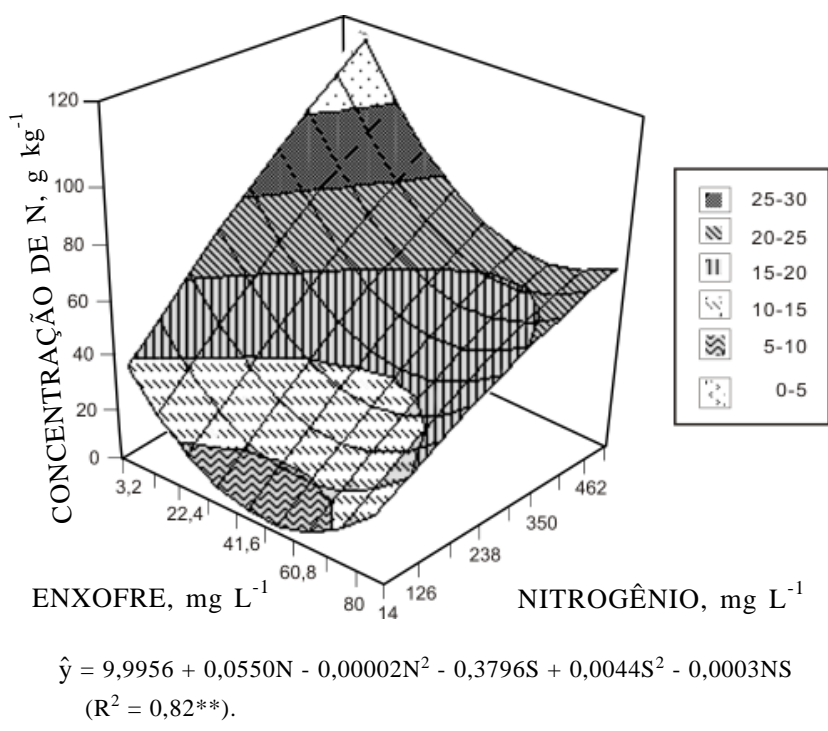

Figura 5. Concentração de nitrogênio nas raízes do capim-Marandu, considerando as combinações de doses de nitrogênio e de enxofre aos 79 dias do transplantio.

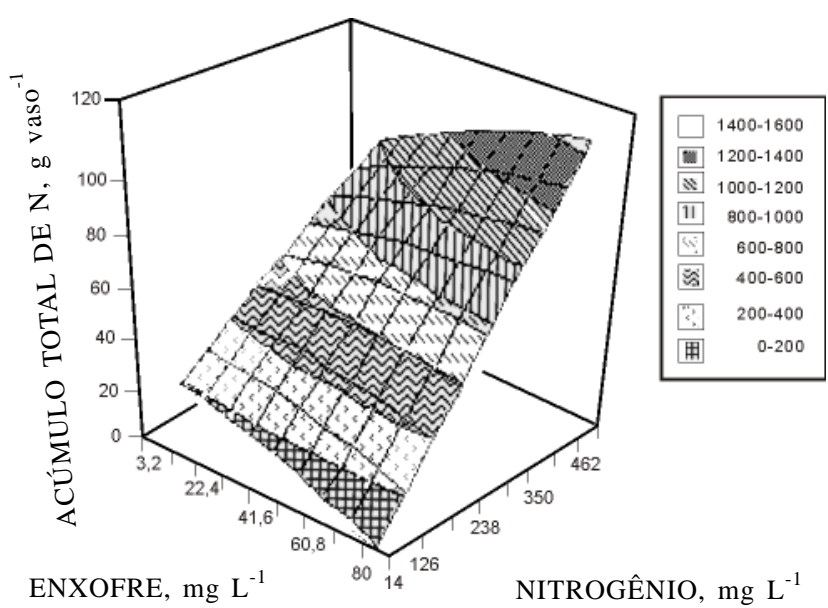

$=154,1237+1,9812 \mathrm{~N}-0,0005 \mathrm{~N}^{2}-0,2863 \mathrm{~S}+0,0318 \mathrm{~S}^{2}-0,0180 \mathrm{NS}$ $\left(\mathrm{R}^{2}=0,85^{* *}\right)$.

Figura 6. Acúmulo total de nitrogênio no capimMarandu, considerando as combinações de doses de nitrogênio e de enxofre aos 79 dias do transplantio.

\section{Concentração e acúmulo total de enxofre}

$\mathrm{Na}$ análise de variância para a concentração de $\mathrm{S}$ nas raízes do capim-Marandu, não se observou significância para a interação entre as doses de $\mathrm{Ne}$ as de S na solução nutritiva. Entretanto, observou-se significância para as doses individuais de N, com os resultados tendo ajuste ao modelo de regressão de primeiro grau (Figura 7). O incremento na dose de N na solução nutritiva resultou em redução da concentração de $\mathrm{S}$ nas raízes.
A mais baixa dose de $\mathrm{N}\left(14 \mathrm{mg} \mathrm{L}^{-1}\right)$ promoveu a máxima concentração de $\mathrm{S}\left(2,59 \mathrm{~g} \mathrm{~kg}^{-1}\right)$, enquanto altas doses de $\mathrm{N}$ acarretavam a concentração mais baixa de $\mathrm{S}\left(0,43 \mathrm{~g} \mathrm{~kg}^{-1}\right)$ nas raízes. Isto pode ser devido ao efeito de diluição, uma vez que, à medida que se aumentou a dose de N, observou-se incremento da massa seca de raízes (Figura 2). Esses resultados de concentração de $\mathrm{S}$ demonstram a necessidade de cuidar do fornecimento de $\mathrm{S}$, quando o $\mathrm{N}$ é suprido em quantidade apreciável para o capim-Marandu, para que a relação entre $\mathrm{N}$ e $\mathrm{S}$ seja adequada.

Para o acúmulo total de S no capim-Marandu, observou-se significância da interação entre as doses de $\mathrm{N}$ e de $\mathrm{S}$ fornecidas na solução nutritiva (Figura 8).

A análise de variância do acúmulo de $\mathrm{S}$ nas raízes do capim-Marandu demonstrou a ocorrência de um ponto de sela. Em condições de dose baixa de S $\left(3,2 \mathrm{~g} \mathrm{~kg}^{-1}\right)$ associada a incrementos nas doses de $\mathrm{N}$, ocorreu redução no acúmulo total de S (Figura 8).

Os valores maiores de acúmulo total de $\mathrm{S}$ foram encontrados em condições de doses altas de N (406 a $\left.462 \mathrm{mg} \mathrm{L}^{-1}\right)$ associadas às doses elevadas de $\mathrm{S}(70,4 \mathrm{a}$ $80 \mathrm{mg} \mathrm{L}^{-1}$ ) no substrato. Ressalta-se, ainda, que valores muito baixos de acúmulo total de $\mathrm{S}$ na planta foram observados em condições de doses elevadas de $\mathrm{N}$ associadas às doses baixas de $\mathrm{S}$. Isto pode ser devido ao fato de que, em condições de altas doses de $\mathrm{N}$, maior era a necessidade da planta pelo S para a manutenção da relação N:S na planta.

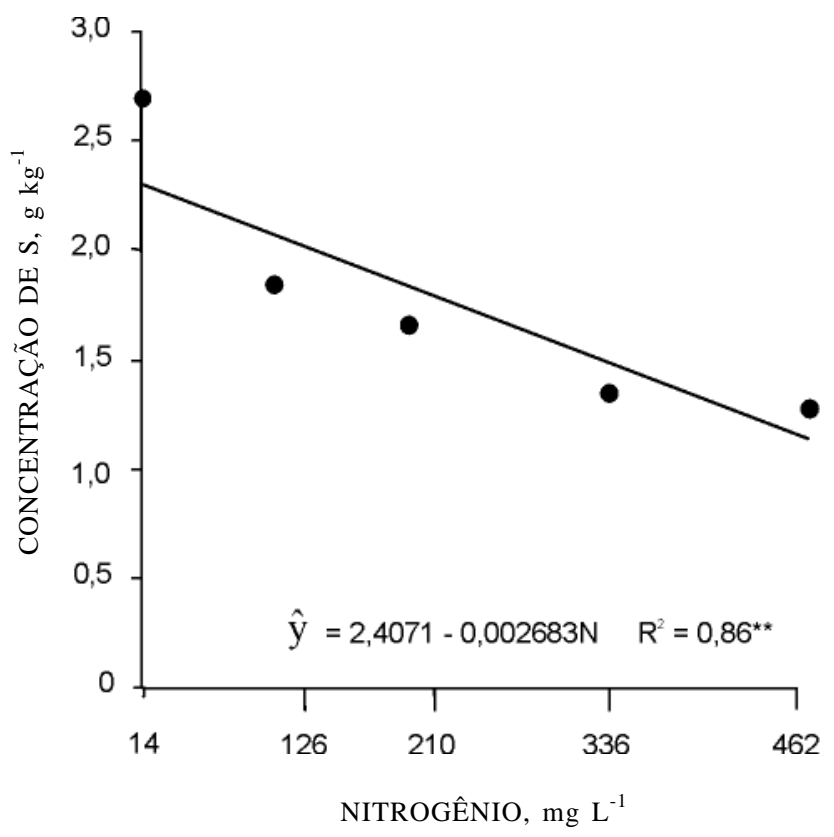

Figura 7. Concentração de enxofre nas raízes do capim-Marandu, considerando as doses de nitrogênio aos 79 dias do transplantio. 


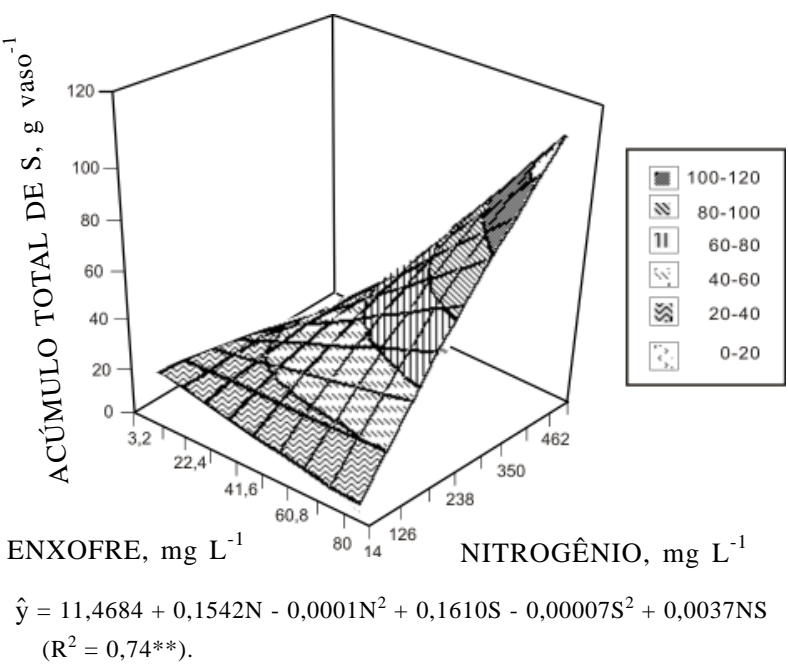

Figura 8. Acúmulo total de enxofre no capimMarandu, considerando as combinações de doses de nitrogênio e enxofre aos 79 dias do transplantio.

\section{Relação N:S nas raízes}

A interação entre as doses de $\mathrm{N}$ e de $\mathrm{S}$ na solução nutritiva não foi significativa para a relação N:S (razão entre as concentrações de $\mathrm{N}$ e de $\mathrm{S}$ no tecido vegetal) nas raízes. Também as respostas na relação N:S nas raízes do capim-Marandu não foram significativas para as doses de $\mathrm{N}$ ou de $\mathrm{S}$. Essa relação teve valor médio de 18:1.

\section{Correlação entre as variáveis do sistema radicular}

A produção de massa seca das raízes correlacionouse significativa e positivamente com o comprimento $\left(\mathrm{r}=0,73^{* *}\right)$ e a superfície $\left(\mathrm{r}=0,81^{* *}\right)$ radiculares, bem como os acúmulos totais de $\mathrm{N}\left(\mathrm{r}=0,68^{* *}\right)$ e de $\mathrm{S}$ $\left(\mathrm{r}=0,64^{* *}\right)$ no capim-Marandu. O comprimento radicular também correlacionou-se positivamente com a superfície radicular $\left(\mathrm{r}=0,74^{* *}\right)$. Ainda, o acúmulo total de S na planta mostrou correlação positiva com o acúmulo total de $\mathrm{N}$ no capim-Marandu $\left(\mathrm{r}=0,82^{* *}\right)$. A correlação entre a concentração total de $\mathrm{N}$ e de S e esses atritubos apresentaram coeficientes muito baixos.

Dos atributos radiculares das gramíneas forrageiras, a produção de massa seca tem sido o mais avaliado (Cecato et al., 2004). Dependendo do porte das raízes, a mesma quantidade de massa seca pode ser obtida com variáveis de comprimento e superfície radiculares. No presente experimento, com capimMarandu, a relação entre o comprimento (Yc) e a massa seca das raízes $(\mathrm{Xm})$ é traduzida pela expressão $\hat{\mathrm{y}}_{\mathrm{c}}=-22,467+68,850 \mathrm{Xm}-1,882 \mathrm{Xm}^{2}\left(\mathrm{R}^{2}=0,66\right)$.

O fato de o acúmulo total de $\mathrm{N}$ no capim ter mostrado significativas correlações com o comprimento, superfície e produção de massa seca radiculares tem especial significado. Particularmente, isto deve ser destacado com relação à produção de massa seca radicular, uma vez que nem sempre ela reflete a participação efetiva na absorção de água e nutrientes, em decorrência da presença de raízes velhas e espessas, como apontado por Mengel \& Kirkby (2001).

\section{CONCLUSÕES}

1. A concentração de $\mathrm{N}$ e os acúmulos totais de $\mathrm{N}$ e de $\mathrm{S}$ no capim-Marandu mostraram-se dependentes da interação entre as doses de $\mathrm{N}$ e de $\mathrm{S}$.

2. $\mathrm{O} \mathrm{N}$ exerceu efeito determinante no comprimento, na superfície, na produção de massa seca de raízes e na concentração de $\mathrm{S}$ e na relação comprimento:massa seca do sistema radicular do capim-Marandu.

3. A dose de $\mathrm{N}$ de, no mínimo, $400 \mathrm{mg} \mathrm{L}^{-1}$ foi necessária para maximizar o comprimento, a superfície e a produção de massa seca das raízes da gramínea.

4. O comprimento, a superfície e a produção de massa seca de raízes e o total de $\mathrm{N}$ acumulado nas plantas correlacionaram-se positivamente entre si.

\section{AGRADECIMENTO}

Os autores agradecem à FAPESP, pela concessão da bolsa de mestrado e pelo apoio institucional prestado para a realização deste trabalho.

\section{LITERATURA CITADA}

ALCÂNTARA, P.B. \& BUFARAH, G. Plantas forrageiras gramíneas e leguminosas. São Paulo, Nobel, 1992. 150p.

BATISTA, K. \& MONTEIRO, F.A. Respostas morfológicas e produtivas do capim-marandu a doses combinadas de nitrogênio e de enxofre. R. Bras. Zootec., 35:1281-1288, 2006.

BROWER, R. Nutritive influences on the distribution of dry matter in the plant. Nether. J. Agric. Sci., 10:342-399, 1962.

CECATO, U.; JOBIM, C.C.; REGO, A. \& LENZI, A. Sistema radicular-componente esquecido das pastagens. In: SIMPÓSIO SOBRE MANEJO ESTRATÉGICO DA PASTAGEM, 2., Viçosa, MG, 2004. Anais. Viçosa, Universidade Federal de Viçosa, 2004. p.159-207.

CRESTANA, S.; GUIMARÃES, M.F.; JORGE, L.A.C.; RALISCH, R.; TOZZI, C.L.; TORRE, A. \& VAZ, C.M.P. Avaliação da distribuição de raízes no solo auxiliada por processamento de imagens digitais. R. Bras. Ci. Solo, 18:365-371, 1994. 
EMPRESA BRASILEIRA DE PESQUISA AGROPECUÁRIA EMBRAPA. CNPDIA. SIARCS 3.0. São Carlos, s/d.

ESHEL, A. \& WAISEL, Y. Multiform and multifunction of various constituents of one root system. In: WAISEL, Y., ESHEL, A. \& KAFKAFI., U., ed. Plant roots: The hidden half. 2. ed. New York, Marcel Dekker,1996. p.175-192.

FITTER, A. Characteristics and functions of root systems. In: WAISEL, Y.; ESHEL, A. \& KAFKAFI., U., ed. Plant roots: the hidden half. 2.ed. New York, Marcel Dekker,1996. p.1-29.

GOMES, F.P. \& CONAGIN, A. Experimentos de adubação: Planejamento e análise estatística. In: EMPRESA BRASILEIRA DE PESQUISA AGROPECUÁRIA. Métodos de pesquisa em fertilidade do solo. Brasília, 1991. p.103-144.

GUEDES, L.M.; GRAÇA, D.S.; MORAIS, M.G.; ANTUNES, R.C. \& GONÇALVES, L.C. Influência da aplicação de gesso na produção de matéria seca, na relação nitrogênio:enxofre e concentrações de enxofre, cobre, nitrogênio e nitrato em pastagens de Brachiaria decumbens Stapf. Arq. Bras. Med. Vet. Zootec., 52:521$526,2000$.

GUENNI, O.; MARIN, D. \& BARUCH, Z. Response to drought of five brachiaria species. I. Biomass production, leaf growth, root distribution, water use and forage quality. Plant Soil, 243: 229-241, 2002.

LAVRES JUNIOR, J. Combinações de doses de nitrogênio e potássio para o capim-Mombaça. Piracicaba, Escola Superior de Agricultura "Luiz de Queiroz", 2001. 103p. (Tese de Mestrado)

LITTELL, R.C. \& MOTT, G.O. Computer assisted design and analysis of response surface experiments in agronomy. Soil Crop Sci. Soc. Fla. Proc., 34:94-97, 1975.
MARSCHNER, H. Mineral nutrition of higher plants. 2.ed. London, Academic Press, 1995. 889p.

MENGEL, K. \& KIRKBY, E. Principles of plant nutrition. 5.ed. Dordrecht, Kluwer Academic Publishers, 2001. 849p.

MONTEIRO, F.A. \& CARRIEL, J.M. Aplicação de níveis de enxofre na forma de gesso para o cultivo do capimColonião em dois solos arenosos do Estado de São Paulo. B. Indústr. Animal, 44:335-347, 1987.

SANTOS, A.R. \& MONTEIRO, F.A. Produção e perfilhamento de Brachiaria decumbens Stapf. em função de doses de enxofre. Sci. Agric., 56:689-692, 1999.

SANTOS JUNIOR, J.D.G. Dinâmica de crescimento e nutrição do capim-Marandu submetido a doses de nitrogênio. Piracicaba, Escola Superior de Agricultura "Luiz de Queiroz", 2001. 79p. (Tese de Mestrado)

SARRUGE, J.R. Soluções nutritivas. Summa Phytopathol., 1:231-233, 1975.

SARRUGE, J.R. \& HAAG, H.P. Análises químicas em plantas. Piracicaba, Escola Superior de Agricultura "Luiz de Queiroz", 1974. 56p.

SAS INSTITUTE. The SAS-system for windows: Release 6.08 (software). Cary, 1996.

TERUEL, D.A.; DOURADO NETO, D.; HOPMANS, J.W. \& REICHARDT, K. Modelagem matemática como metodologia de análise do crescimento e arquitetura de sistemas radiculares. Sci. Agric., 57:683-691, 2000.

WERNER, J.C. \& MONTEIRO, F.A. Respostas das pastagens a aplicação de enxofre. In: SIMPÓSIO: ENXOFRE E MICRONUTRIENTES NA AGRICULTURA BRASILEIRA, 1., Londrina, 1988. Anais. Londrina, Embrapa, CNPS; IAPAR: Londrina, 1988. p.87-102. 